\title{
Endoscopic Versus Free Hand Insertion of the Ventricular Catheter in Ventriculo- Peritoneal Shunt
}

\author{
W.A.Badawy, M.M.Adawy, A.A.Arab and A.M.E.Abdel-Lateef
}

Neurosurgery Dept., Faculty of Medicine, Benha Univ., Benha, Egypt

E-Mail:ahmed85@gmail.com

\begin{abstract}
Hydrocephalus is a disturbance of cerebrospinal fluid [CSF] formation, flow, or absorption, leading to an increase in volume occupied by this fluid in the central nervous system. It is either communicating or non-communicating. On assess ventricular catheter placement Possibly for anatomic landmark-guided free hand placement or endoscopic helped placement in regards to intraoperative parameters What's more postoperative Conclusion. This examine might have been a explanatory investigation led ahead [60] patients for hydrocephalus undergoing VP shunt were haphazardly ordered under 2 groups, [30] for free hand insertion and the other [30] with endoscopic guided insertion. Concerning illustration respect our study there might have been critical statistically Contrast $[\mathrm{P}$ esteem $=0.010]$ in regards to Subgalial collection, spoiling What's more glitch the middle of two groups, there is no huge statistically Contrast viewing Vomiting, Fits, sd Hygroma , Fever, SDH What's more Pneumocephalous the middle of two aggregations. In spite of expositive expression proposes that new innovative developments including navigation, ultrasonography What's more endoscope enhance ventricular catheter position especially clinched alongside challenging cases, free-handed system customized as stated by those head and ventricular setup In view of pre-operative ct mind could provide for acceptable ventricular catheter position, particularly in the control about an encountered specialist.
\end{abstract}

Keywords: Cerebrospinal fluid, Hydrocephalus, Ventricular and endoscopic.

\section{Introduction}

Hydrocephalus may be a aggravation about cerebrospinal liquid [CSF] formation, flow, alternately absorption, prompting a expansion done volume involved Eventually Tom's perusing this liquid in the focal apprehensive framework. It may be Possibly conveying alternately non-communicating [1].

Surgical medicine is the favored restorative choice On patients with hydrocephalus [2].

Ventricular shunt placement for treating hydrocephalus will be a standout amongst the practically as a relatable point neurosurgical methods [3]. Ventriculo-peritoneal [VP] shunt placement will be those backbone for medication to hydrocephalus in both grown-up Also pediatric patients [4].

Notwithstanding progresses done shunt catheter materials and the valves used, there remains An secondary rate about shunt disappointment [5].

The The greater part as a relatable point reason for shunt glitch is the vicinity of the choroid plexus Also catheter tip which prompt impediment about ventricular catheter [6].

To minimize this problem, surgeons endeavor should spot the ventricular catheter away starting with those choroid plexus in the frontal horn, over those foramen for Monro, alternately in the occipital horn, an undertaking the vast majority frequently attained utilizing anatomic landmarks [7]. There need aid various publications in the writing thinking about endoscopic support alternately picture direction to free hand ventricular catheter placement [8]. By analyzings endoscopically versus nonendoscopically set ventricular catheters, information need demonstrated that endoscopic ventricular catheter placement lessens those chances about proximal obstruction, in spite of the fact that it didn't diminishing those generally disappointment rate [9].

\section{Subjects and methods}

This study was an analytical study conducted on [60] patients with hydrocephalus undergoing VP shunt were randomly classified into 2 groups, [30] with free hand insertion and the other [30] with endoscopic guided insertion.

\section{Site and time of the study}

The study was conducted at Benha University Hospital and El-Mansoura New General Hospital. From July 2016 to July 2018

Inclusion Criteria: All patients with hydrocephalus whether communicating or non-communicating, were included in the study without privilege to age and gender

Exclusion Criteria: Hydrocephalic changes with intra ventricular hemorrhage or infection, Medically unfit patient and Recurrent patient.

All patients involved in this study were subjected to: Preoperative assessment 1. Clinical assessment through: Complete medical history, Complete general examination and Complete neurological examinations. Neuroimaging studies: CT \pm MRI

\section{Operation: Pre-operative preparation}

Informed written surgical consent obtained from the patient or relative, All patient received pre-operative prophylactic antibiotic and Checking endoscopic equipment. [for endoscopic group]. Intra-operative assessment: 60 Patients with hydrocephalus undergoing VP shunt were randomly divided into two groups

1. [30] with anatomical landmark-guided free hand insertion and

2. [30] with endoscopic guided insertion of ventricular catheter: The following data were reported, Intraoperative difficulties and complications, Time of operation, Risks associated with endoscopic shunt placement and Amount of bleeding. 


\section{Surgical procedure}

The greater part patients were worked under general anesthesia, Positioning as stated by pre-planned agent site, fitting cleaning Also shaving, skin entry point for climbing of a galial -periceranial flap, burr gap at pre wanted site. [Kocher's purpose or Frazier's point], dural searing Also entry point over cruciate manner, tapping those ventricle for presenting those endoscope. Or shunt for freehand group, investigation Also introduction of the ventricular life structures. [for endoscopic group], watering system for warm ringer lactate answer for keep ventricular breakdown What's more freedom from claiming dying. [for endoscopic group], Placement of a shunt under immediate visualization. [for endoscopic group], in the event about uncontrolled dying a outside waste framework might have been utilized What's more Conclusion done anatomic layers.

\section{Post-operative management}

The greater part patients were evaluated postoperatively: Clinically centering once postoperative event about neurological deficits, Seizures, Vomiting, CSF leak, shunt disappointment Furthermore shunt contamination. Radiological evaluation [CT $\pm \mathrm{MRI}$ on show correct catheter placement, What's more avoid difficulties.

\section{Results}

Table (1) The mean age of patients of Free Hand group was [52.63 months], ranged from 1 month to 180 months while The mean age of patients of Endoscopic group was [46.67 months], ranged from 6 months to 180 months. As regard the gender of patients, there were 19 [63.3\%] Male, 11 [36.7\%] Female in Free Hand group patients and 16 [53.3\%] Male, 14 [46.7\%] Female in Endoscopic group .The Vomiting was[ 14 [46.7\%] ] +ve , [16 [53.3\%] $-\mathrm{ve}$ in Free Hand group and [16 [53.3\%] +ve , [ 14 [46.7\%] ] -ve in Endoscopic group. The Fits were [4 [13.3\%] ] +ve , [26 [86.7\%] -ve in Free Hand group and [5 [16.7\%] +ve , [ 25 [83.3\%] ] -ve in Endoscopic group.

Table (2) There is significant statistically difference [P value $=0.001 *]$ in Operative time between two groups with Mean 92.2 in Free Hand group and 110.57 in Endoscopic group.

Table (3) There is significant statistically difference [P value $=0.001 *]$ in Accuracy of catheter tip placement between two groups regarding G1, also significant statistically difference $\left[\mathrm{P}\right.$ value $\left.=0.005^{*}\right]$ regarding $\mathrm{G} 2$ and significant statistically difference $\left[\mathrm{P}\right.$ value $=0.009^{*}$ ] regarding $\mathrm{G} 4$, this significant statistically difference is for Endoscopic group.

Table (4) There is no significant statistically difference $[\mathrm{P}$ value $=0.284]$ in Hospital stay between two groups with Mean 2.23 rang from [1-4] day in Free Hand group and 2.5 rang from [1-5] day in Endoscopic group.

Table (5) There is significant statistically difference [P value $=0.010]$ regarding Subgalial collection, in Infection and Malfunction between two groups .There is no significant statistically difference regarding Vomiting, Fits, SD Hygroma, Fever, SDH and Pneumocephalous between two groups.

Table (1) Age, sex, vomiting, fits and [6th nerve palsy] incidence.

\begin{tabular}{|c|c|c|c|}
\hline & \multicolumn{2}{|c|}{ Free Hand } & Endoscopic \\
\hline \multirow{2}{*}{ Age [months] } & Range & $1-180$ & $6-180$ \\
\hline & Mean \pm SD & $52.63 \pm 38.53$ & $46.67 \pm 42.72$ \\
\hline Sey & Male [\%] & $19[63.3 \%]$ & $16[53.3 \%]$ \\
\hline sex & Female $[\%]$ & $11[36.7 \%]$ & $14[46.7 \%]$ \\
\hline Vomiting & \multicolumn{2}{|c|}{ Free Hand } & Endoscopic \\
\hline \multirow{2}{*}{ +ve } & $\mathrm{N}$ & 14 & 16 \\
\hline & $\%$ & $46.7 \%$ & $53.3 \%$ \\
\hline \multirow{2}{*}{$-v e$} & $\mathrm{~N}$ & 16 & 14 \\
\hline & $\%$ & $53.3 \%$ & $46.7 \%$ \\
\hline \multirow{2}{*}{ Total } & $\mathrm{N}$ & 30 & 30 \\
\hline & $\%$ & $100.0 \%$ & $100.0 \%$ \\
\hline \multirow[t]{2}{*}{ Fits } & & Free Hand & Endoscopic \\
\hline & $\mathrm{N}$ & 4 & 5 \\
\hline$+v e$ & $\%$ & $13.3 \%$ & $16.7 \%$ \\
\hline \multirow{2}{*}{-ve } & $\mathrm{N}$ & 26 & 25 \\
\hline & $\%$ & $86.7 \%$ & $83.3 \%$ \\
\hline \multirow{2}{*}{ Total } & $\mathrm{N}$ & 30 & 30 \\
\hline & $\%$ & $100.0 \%$ & $100.0 \%$ \\
\hline \multirow[t]{2}{*}{$6^{\text {th }}$ nerve palsy } & \multicolumn{2}{|c|}{ Free Hand } & Endoscopic \\
\hline & $\mathrm{N}$ & & 8 \\
\hline \multirow{2}{*}{ +ve } & $\%$ & & $26.7 \%$ \\
\hline & $\mathrm{N}$ & & 22 \\
\hline$-v e$ & $\%$ & & $73.3 \%$ \\
\hline \multirow{2}{*}{ Total } & $\mathrm{N}$ & & 30 \\
\hline & $\%$ & $.0 \%$ & $100.0 \%$ \\
\hline
\end{tabular}


Table (2) Operative time

\begin{tabular}{lcccc}
\hline Operation time [min] & Free Hand & Endoscopic & T. test & P. value \\
\hline Range & $85-101$ & $99-125$ & \multirow{2}{*}{114.366} & $0.001^{*}$ \\
Mean \pm SD & $92.20 \pm 4.87$ & $110.57 \pm 8.05$ & & \\
\hline
\end{tabular}

Table (3) Accuracy of catheter tip placement

\begin{tabular}{|c|c|c|c|c|c|}
\hline $\begin{array}{l}\text { Accuracy of catheter tip } \\
\text { placement }\end{array}$ & & Free Hand & Endoscopic & $\mathbf{X}^{2}$ & P-value \\
\hline G 1 & $\begin{array}{l}\mathbf{N} \\
\%\end{array}$ & $\begin{array}{c}10 \\
33.3 \%\end{array}$ & $\begin{array}{c}26 \\
86.7 \%\end{array}$ & 17.779 & $0.001 *$ \\
\hline G 2 & $\begin{array}{l}\mathbf{N} \\
\%\end{array}$ & $\begin{array}{c}14 \\
46.7 \%\end{array}$ & $\begin{array}{c}4 \\
13.3 \%\end{array}$ & 7.942 & $0.005^{*}$ \\
\hline G 4 & $\begin{array}{l}\mathrm{N} \\
\%\end{array}$ & $\begin{array}{c}6 \\
20.0 \%\end{array}$ & $\begin{array}{c}0 \\
.0 \%\end{array}$ & 6.672 & $0.009^{*}$ \\
\hline Total & $\begin{array}{l}\mathrm{N} \\
\%\end{array}$ & $\begin{array}{c}30 \\
100.0 \%\end{array}$ & $\begin{array}{c}30 \\
100.0 \%\end{array}$ & & \\
\hline
\end{tabular}

Table (4) Hospital stay

\begin{tabular}{lcccc}
\hline Hospital stay & Free Hand & Endoscopic & T. test & P. value \\
\hline Range & $1-4$ & $1-5$ & \multirow{2}{*}{1.170} & 0.284 \\
Mean \pm SD & $2.23 \pm 0.82$ & $2.50 \pm 1.07$ & & \\
\hline
\end{tabular}

Table (5) post-operative complication

\begin{tabular}{lcccccc}
\hline Complications & \multicolumn{2}{c}{ Free Hand [N=30] } & Endoscopic $[\mathbf{N}=\mathbf{3 0}]$ & $\mathbf{X}^{\mathbf{2}}$ & P-value \\
\hline & $\mathrm{N}$ & $\%$ & $\mathrm{~N}$ & $\%$ & & \\
Vomiting & 8 & 26.7 & 6 & 20 & 0.373 & 0.542 \\
Fits & 5 & 16.7 & 4 & 13.3 & 0.131 & 0.718 \\
SD Hygroma & 2 & 6.7 & 7 & 23.3 & 3.268 & 0.071 \\
Fever & 8 & 26.7 & 5 & 16.7 & 0.884 & 0.347 \\
Subgalial collection & 0 & 0 & 6 & 20 & 6.667 & $0.010^{*}$ \\
SDH & 9 & 30 & 6 & 20 & 0.800 & 0.371 \\
Pneumocephalous & 9 & 30 & 7 & 23.3 & 0.341 & 0.559 \\
Infection & 6 & 20 & 0 & 0 & 6.667 & $0.010^{*}$ \\
Malfunction & 6 & 20 & 0 & 0 & 6.667 & $0.010^{*}$ \\
\hline
\end{tabular}

Case [1] [Kocher's point] Free-hand insertion 4 years male with $\mathrm{HCP}$

Personal history: Male aged 4 years old.

Complain: Vomiting.

CT brain findings: $\mathrm{HCP}$

Operative data:

Patient was operated in supine position, with the head in neutral position, right frontal bur hole was done, abdominal incision, insertion of a ventricular and peritoneal catheters.

Post-operative care:
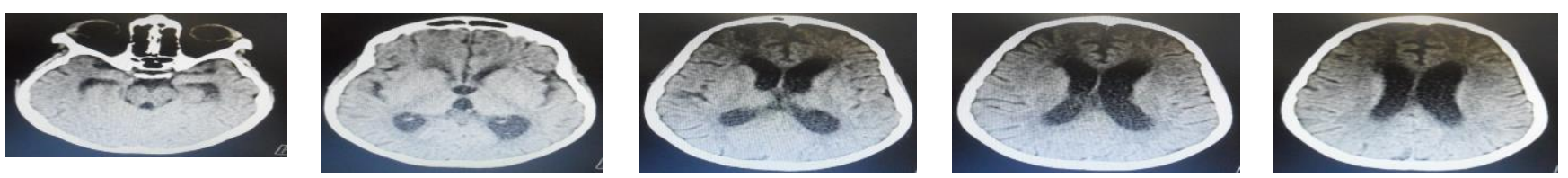

Fig (1) CT pre Op.
Patient was admitted to ICU under observation for 24 hours. Discharged to ward for another day then from hospital on 3rd day of surgery with no complication.

Follow up:

The patient was followed up early and late after surgery clinically and radiologically.

Clinically: Vomiting stopped.

Radiologically: CT brain showed acceptable shrinkage of the ventricular size, and tip of catheter at foramen of Monoro G1. 


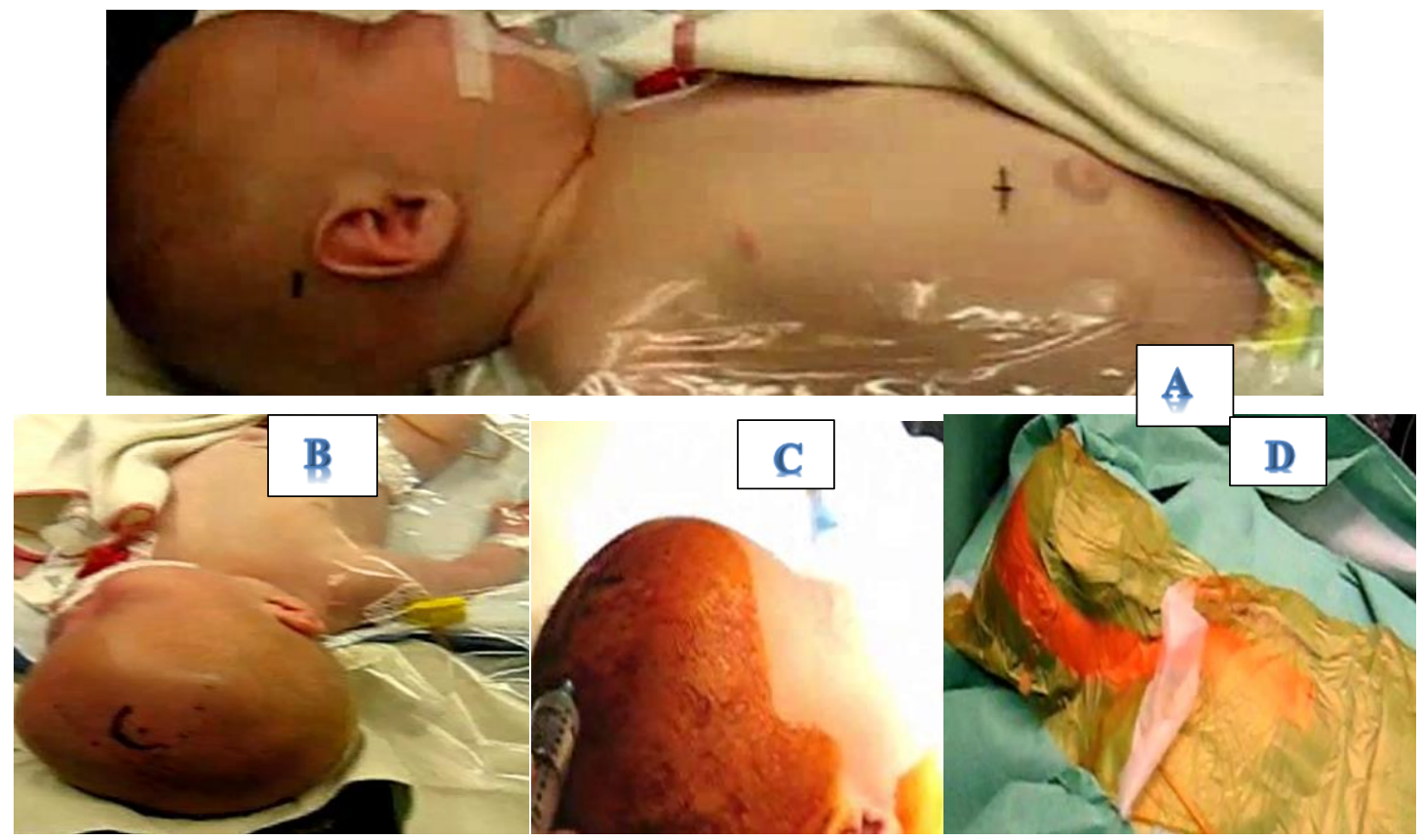

Fig (2) [A] patient in supine position, head rotated to left,marker on abdominal incision. [B] Marker for frontal incision. [C] Subcutaneous Injection of adrenaline and mebacaine. [D] Offsite application.
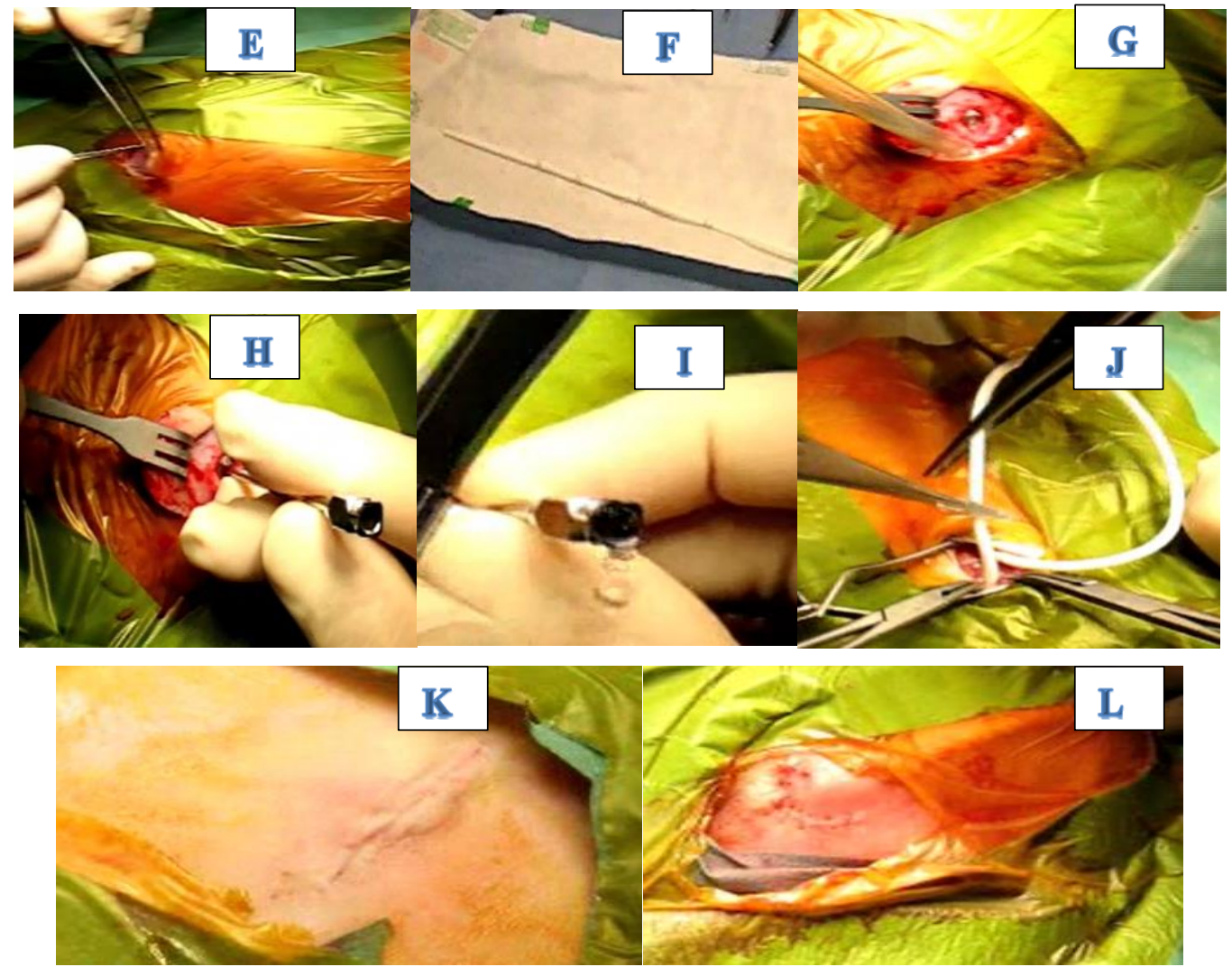

Fig (3) [E] Right frontal incision. [F] Ventricular catheter. [G] Frontal burr hole done,[Kocher's point].[H] Brain cannula insertion. [I] CSF came out. [J] Insertion of peritoneal catheter. [K] After suturing abdominal incision. [L] After suturing frontal incision. 


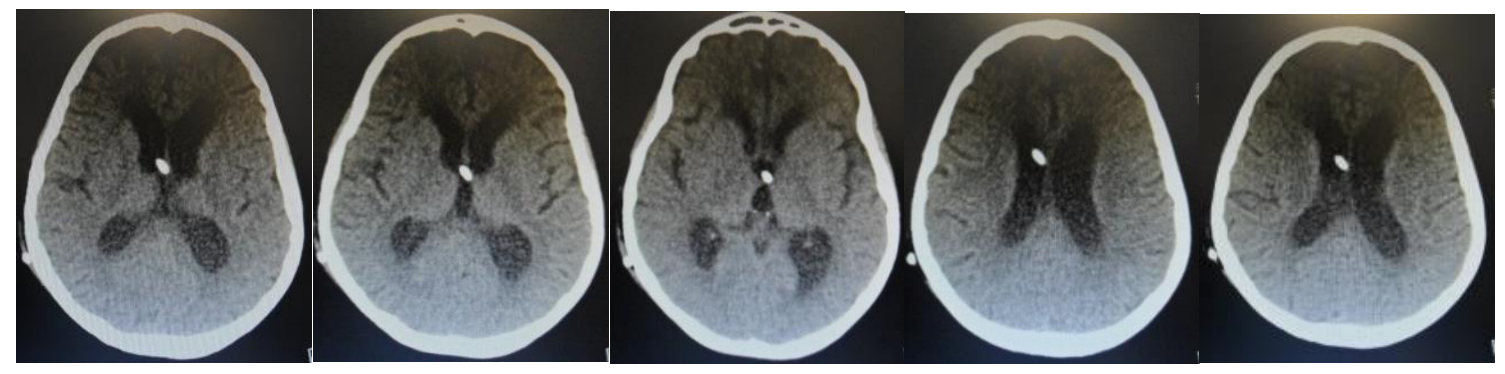

Fig (4) CT post Op

\section{Discussion}

Over our study, there may be huge statistically Contrast $\left[\mathrm{P}\right.$ worth $\left.=0.001^{*}\right]$ Previously, agent chance the middle of two gatherings with imply 92. 2 in free hand bunch Also 110. 57 to endoscopic aggregation.

There is no huge statistically distinction $[\mathrm{P}$ worth $=0$. 132] On technique duration of the time between two bunches with imply 47.93 to free hand gathering What's more 49. 57 Previously, endoscopic aggregation.

Same time free-hand system is performed as stated by anatomic landmarks, a few propelled strategies including stereotaxic navigation, ultrasonography, and endoscopy need aid prescribed to enhance the nature of catheter placement [7], [9].

There will be noteworthy statistically distinction $[\mathrm{P}$ quality $=0.001 *]$ clinched alongside correctness from claiming catheter tip placement the middle of two bunches in regards G1, Additionally huge statistically distinction $\left[\mathrm{P}\right.$ worth $\left.=0.005^{*}\right]$ viewing $\mathrm{G} 2$ and huge statistically Contrast $[\mathrm{P}$ quality $=0.009 *$ ] viewing G4, this critical statistically distinction will be to endoscopic one assembly.

This is consent with, [10] examine which accounted for that those occurrence of shunt glitch might have been exact low The point when those ventricular catheter tip might have been put to ipsilateral frontal horn.

To An investigation of 114 kids for VPSs, [11] found that best $55 \%$ of the catheter tips were spotted over a great position, characterized Likewise in the ipsilateral frontal horn, foremost of the foramen about monroe. Similarly, throb Furthermore Grabb indicated 53\% fantastic ventricular catheter placement to 160 Youngsters for VPS. As much evaluating for catheter position might have been In view of stereotactic coordinates ascertained for plain skull X-beam movies and corresponded approximately will area inside the ipsilateral frontal horn, foremost of the foramen from claiming monroe.

This coaptted with our contemplate as $86.7 \%$ over endoscopic one assembly g 1, 13. 3\% On endoscopic gathering G2 Furthermore nobody for G4, same time over free hand gathering there might have been $33.3 \%$ for G1, 46. 7\% Previously, G2 What's more $20.0 \%$ over G4.

There is no huge statistically distinction $[\mathrm{P}$ esteem $=0$. 284 ] for healing center sit tight between two bunches for imply 2. 23 rang from [1-4] day done free hand assembly What's more 2. 5 rang starting with [1-5] day over endoscopic bunch.
Likewise see our examine there might have been critical statistically distinction $[\mathrm{P}$ quality $=0.010]$ in regards Subgalial collection, spoiling What's more glitch between two groups, this concur for [9] who news person that significant reason for shunt glitch incorporate obstruction, infection, What's more malposition. It need been accounted for that free-hand system brings about malposition of the shunt Previously, 12. 3-44\% for situations.

A standout amongst those mossycup oak essential difficulties clinched alongside patients with ventricular catheters is catheter glitch Concerning illustration Theodosopoulos et al. , accounted for on account of VPS, the practically regular reason for glitch is block of the ventricular catheter from tissue in the region of the catheter tip.

There may be no critical statistically distinction in regards Vomiting, Fits, sd Hygroma, Fever, SDH Also Pneumocephalous between two bunches.

Endoscopic see could be used to spot those ventricular catheter Previously, a great position inside those ventricular framework endoscopic see could be used to spot the ventricular catheter Previously, a great position inside the ventricular framework. Endoscopic see might a chance to be used to put those ventricular catheter to a great position inside the ventricular framework [13].

In spite of writing proposes that new innovative developments including navigation, ultrasonography Also endoscope move forward ventricular catheter position especially over challenging cases, free-handed technobabble customized as stated by those mind What's more ventricular setup dependent upon pre-operative ct cerebrum could provide for acceptable ventricular catheter position, particularly in the hands about a encountered specialist [8].

\section{Conclusion \& Recommendations}

Although literature suggests that new technological advances including navigation, ultrasound and endoscope improve ventricular catheter position particularly in difficult cases, free-handed technique tailored according to the head and ventricular configuration based on preoperative CT brain can give satisfactory ventricular catheter position, especially in the hands of an experienced surgeon. 


\section{References}

[1] H.L. Rekate, A contemporary definition and classification of hydrocephalus. Semin Pediatr Neurol. Mar, Vol.16(1), PP.9-15,2009.

[2] M.G. Hamilton, Treatment of hydrocephalus in adults. Semin Pediatr Neurol. Mar, Vol.16(1), PP.34-41,2009.

[3] C.L.Nesvick, N.R.Khan, G.U.Mehta, and P. Jr.Klimo,Image Guidance in Ventricular Cerebrospinal Fluid Shunt Catheter Placement: A Systematic Review and Meta-Analysis. Neurosurgery, Vol.77(3), PP.321$31,2015$.

[4] Khan.Farid , Rehman.Abdul , S. Shamim. Muhammad , and E. Bari Muhammad, Factors affecting ventriculoperitoneal shunt survival in adult patients Surg Neurol Int, Vol. 6,PP. 25,2015.

[5] GK.Reddy, P.Bollam, R.Shi, B.Guthikonda, and A.Nanda,Management of adult hydrocephalus with ventriculo-peritoneal shunts: long term single institution experience. J Neurosurg, Vol. 69,PP.774 $781,2011$.

[6] E.Domenech, C.Di Rocco, T.Mehmet, J.Georg, and F.M.Juan, Complications of CSF shunting in hydrocephalous prevention, identification and management [Neuroimaging in CSF shunt complications, Ch.:3 p46, 47, Springer International Publishing Switzerland,2015.

[7] r. W. Kestle.John, m. Drake.james, Lack of benefit of endoscopic ventriculoperitoneal shunt insertion: a multicenter randomized trial. J Neurosurg, Vol.98,PP.284-290,2003.

[8] S.M.Hamada,andA.H.1.Abou-Zeid, Pediatric Ventriculo-peritoneal Shunt - Is Free Hand Placement of Ventricular Catheter Still Acceptable? Egyptian Journal of Neurosurgery , Vol. 30 (3) ,PP.195$198,2015$.

[9] T.J.Wilson, W.R.Jr Stetler , W.N.Al-Holou , Comparison of the accuracy of ventricular catheter placement using freehand placement, ultrasonic guidance, and stereotactic neuro navigation. $\mathbf{J}$ Neurosurg; vol.18, PP.201-213, 2013.

[10] D.M1.Arman, S.M2.Ekramullah S.K3.Mukherjee ， I4.Joynul , M.H5.Rashid , M.A6.Salam, M.A7.Quddus , A.Z.M8.Saifuddin, M.S9.Arefin DOI: https: //doi. org/10.3329/bjns.v9i1.42919 Bang. J Neurosurgery; vol.9(1), PP.16-21,2019,

[11] A.L.Albright, S.J.Haines, F.H.Taylor,Function of parietal and frontal shunts in childhood hydrocephalus. J Neurosurgery, Vol.69, PP.883-886,1988.

[12] Sarkari A, S.A.Borkar, A.K. Mahapatra, Anal extrusion of migrated ventriculo-peritoneal shunt catheter: an unusual complication and review of literature. Asian J Neurosurg, Vol.11,PP.459,2016.

[13] F.R.Romero, Ventriculoperitoneal Shunt assisted by Neuroendoscopy - experience of 36 cases Ann Acad Med Stetin, Vol.52(3), PP.85-9,2006. 